\title{
MANIFESTACIONES DE LA CRISE EN AMERICA LATINA Y LAS PARADOJAS DEL NEODESARROLISMO ARGENTINO
}

\author{
Claudio Katz*
}

\begin{abstract}
El agravamiento de la crisis global acentúa las limitaciones de la economía latinoamericana para atemperar la turbulencia. Aumenta la centralidad de UNASUR, pero el fondo de estabilización no contrarresta la extranjerización de las finanzas y el estancamiento del Banco del Sur. Las enormes reservas terminarán socorriendo a los banqueros europeos, si no hay avances en la moneda común. El extractivismo exportador impide repetir el desarrollo manufacturero asiático y refuerza la preeminencia de las empresas transnacionales. Los planes asistenciales no reducen la desigualdad, ni atemperan la superexplotación, mientras la lumpen-burguesía del narcotráfico potencia la marginalidad social. El desprestigio neoliberal ha resucitado los enfoques neo-desarrollistas, pero la sustitución de las viejas burguesías nacionales por grupos exportadores obstruye los proyectos de reindustrialización. En este contexto si plantea la posibilidad de una tercera vía verdaderamente popular.

PALABRAS-ClavE: Crisis. Neoliberalismos transnacionales. Neo desarrollismo. América Latina, Argentina.
\end{abstract}

Al concluir el año 2011, reaparecen los nubarrones sobre la economía latinoamericana. El brusco agravamiento de la crisis global augura un freno del crecimiento que aumenta el nerviosismo. Durante el último quinquenio, el producto bruto regional mantuvo un ritmo ascendente del 5\% anual, a pesar de la desaceleración registrada en el 2009. La recuperación posterior se prolongó durante el 2011, que finalizaría con un incremento de $4,4 \%$ del PBI. Hay previsiones de otro aumento del 4,1\% para el 2012, pero nadie sabe cuánto durarán los escudos protectores frente a la nueva turbulencia internacional.

Los neoliberales advierten contra la recaída y proponen recortar el gasto público para reforzar las defensas. Aunque la deuda pública y privada es muy inferior al promedio de los países desarrollados, promueven la contracción para asegurar las acreencias de los banqueros. Sus

* Economista. Investigador. Profesor asociado regular de la cátedra "Economía para historiadores". Departamento de Historia. Facultad de Filosofía y Letras (UBA). Miembro del EDI (Economistas de Izquierda).

Instituto de Investigaciones Económicas Facultad de Ciencias Económicas UBA Córdoba 2120 Buenos Aires. claudiokatz1@gmail.com convocatorias a la austeridad expresan esta prioridad de los financistas. Por el contrario, los heterodoxos alientan la continuidad de políticas contra-cíclicas. Los economistas de CEPAL presentan esta intervención como un acto de transgresión del neoliberalismo, olvidando que, en numerosos países (México, Colombia o Chile), estas medidas complementan la continuidad del libre-comercio y las privatizaciones. Son iniciativas más dependientes de los ingresos fiscales que de las ideologías gubernamentales. ${ }^{1}$ Este intervencionismo no ha sido el único atenuante de la crisis. También la apreciación de las materias primas exportadas, el ingreso de capitales sin oportunidades de inversión en los países centrales y la desincronización del ciclo regional han limitado el impacto del temblor. ${ }^{2}$

Esta combinación de circunstancias se corrobora en la gran heterogeneidad de situaciones nacionales y en la escasa conexión de la reactivación con estrategias peculiares. Se han registrado altas tasas de crecimiento en países con

${ }^{1}$ CEPAL/OIT (2011). Disponível em: www.oit.org.pe ${ }^{2}$ Hemos establecido una comparación con otras conmociones en: Katz (2012a). 
políticas económicas heterodoxas (Argentina) y ortodoxas (Perú) y también resultados inversos en países del primer grupo (Venezuela) y del segundo (México). El efecto atenuado del tsunami global se ha verificado, además, especialmente en el sur del continente. Centroamérica y el Caribe sufren el duro contagio de la recesión estadounidense.

\section{CONFLITOS EN LOS OBJETIVOS FUNDAMENTALES}

Frente a un probable escenario de recesión internacional se multiplican los cónclaves regionales. La frecuencia de estos encuentros contrasta, por ejemplo, con la pérdida de gravitación de las Cumbres Iberoamericanas. UNASUR está logrado una centralidad inédita y comienza a operar como un MERCOSUR ampliado, incorporando a los países que suscribieron Tratados de Libre Comercio con Estados Unidos. El regionalismo sudamericano (Brasil y Argentina) tiende a converger con el área pro-norteamericana del Pacífico (Chile, Colombia, Perú). Esta coexistencia refuerza el predominio de proclamas, en desmedro de iniciativas concretas de integración.

Se discute, en primer lugar, la formación de un fondo de estabilización (FLAT) - a partir de ciertos mecanismos ya existentes (como el FLAR) - para auxiliar a las economías afectadas por corridas cambiarias. La fuga de divisas podría agravarse si los bancos y empresas extranjeras envían más dólares a sus casas centrales, para contrarrestar las situaciones de insolvencia. El FLAT está concebido como un instrumento de protección frente distintos escenarios de vaciamiento financiero. ${ }^{3}$ Pero el monto de recursos comprometido en este resguardo (20.000 millones de dólares) sólo alcanzaría para socorros de emergencia en las economías pequeñas. Este tipo de reacciones defensivas ya se ensayaron en el pasado y no implicaron actos de solidaridad con las víctimas de la especulación. Al contrario, consolidaron una extranjerización del sis-

${ }^{3}$ Varias evaluaciones de esta iniciativa en: Páez (2011); Kulfas (2011); Robba (2011). tema bancario latinoamericano, que sería reafirmada si prospera la propuesta de asociar el FLAT con nuevos préstamos del BID.

En otros encuentros se debaten ideas para avanzar hacia la formación de alguna moneda común. La experiencia del Sucre - que utilizan Venezuela, Ecuador y Bolivia como unidad de cuenta para el intercambio comercial - es la referencia de estos proyectos. Ese signo permite reducir los costos de las transacciones, pero convive con el dólar sin funcionar como moneda real. Aunque pretende incentivar un desacoplamiento de las divisas fuertes, no reemplaza el control de cambios, ni preserva a los países de los tormentosos flujos de capital. ${ }^{4} \mathrm{El}$ Sucre es una iniciativa más avanzada que los mecanismos de intercambio con billetes locales (Brasil-Argentina) o los convenios de pagos recíprocos (ALADI). Pero se encuentra muy lejos de sentar las bases de una moneda regional, basada en modelos de complementación solidaria opuestos a la centralización neoliberal que moldeó la gestación del euro.

El Banco del Sur es otro termómetro de la parsimonia que domina en los proyectos de integración. Ya han transcurrido varios años desde su constitución formal y aún faltan tres confirmaciones parlamentarias de los siete suscriptores del proyecto. Nadie define el destino de los créditos, y el capital comprometido para la entidad es muy reducido, en comparación a un gigante de la zona como es el BNDES de Brasil. ${ }^{5}$ Pero el tema más relevante ocupa poco espacio en la reflexión regional. ¿Qué hacer con las enormes reservas que acumula América Latina? Como resultado del superávit comercial y la afluencia de divisas, los Bancos Centrales ya atesoran 574.000 millones de dólares. Se ha creado un excedente que contrasta con la enfermedad de vaciamientos sufridos por la zona en los momentos de crisis. ¿Los nuevos recursos respaldarán inversiones productivas coordinadas? ¿O se dilapidarán en ${ }^{4}$ Tovar (2011).

5 Brasil, Venezuela y Argentina aportarían cada uno, 2000 millones de dólares al nuevo Banco, Ecuador y Uruguay sumarían 400 millones y Bolivia y Paraguay contribuirían con 100 millones. 
acciones que perpetúan la dependencia?

La actual indefinición conduciría a la desaparición de los fondos por la misma ruta que ingresaron. La Unión Europea, el gobierno norteamericano y el FMI intentan canalizar las reservas hacia un socorro del sistema financiero mundial. Presentan este auxilio como un "aporte de América Latina” a los economías avanzadas, olvidando la deuda histórica que arrastra el Primer Mundo con la región. Proponen acompañar la compra de títulos europeos que realizarían China y otros BRICS, para apuntalar los bancos quebrados. La adquisición de estos papeles acrecentaría las cuantiosas inversiones que ya tiene Latinoamérica, en esa modalidad de colocaciones.

La participación de Brasil en la cartera del FMI constituyó un primer guiño hacia este nuevo compromiso. En la última reunión del G 20 (Cannes) se reforzó este curso mediante explícitas exigencias de intermediación del cuestionado organismo, en cualquier auxilio financiero a Europa. Este idilio del gobierno brasileño con el FMI no es un dato menor, si se tiene en cuenta que el país es el quinto poseedor internacional de Bonos del Tesoro estadounidenses. ${ }^{6}$

El dinero que se use para rescatar a los financistas europeos será sustraído del FLAT, la moneda común, el Banco del Sur y la integración productiva. Sería el nuevo precio que pagarían Argentina, México y Brasil para continuar participando en el G 20, con iniciativas que reafirman la asociación de las clases dominantes locales con el establishment global. Esta orientación se ubica en las antípodas de dos medidas insoslayables para avanzar hacia una integración regional progresista: la nacionalización de los bancos y la estricta regulación de los flujos de capital.

Estas acciones son indispensables en la coyuntura actual, para definir respuestas conjuntas ante contradictorios procesos de revalorización y desvalorización monetaria. La región ha padecido, en los últimos años, los efectos adversos del ${ }^{6}$ A diciembre del 2010, Brasil sólo era superado, en esas
acreencias, por China, Japón, Gran Bretaña y los países árabes exportadores de petróleo. Ver Moniz (2011). ingreso de dólares (que sobrevaluan la moneda local) y también del egreso de divisas (que provocan las conocidas tensiones cambiarias).

Seguramente, Brasil definiría el rumbo a seguir, desde el momento que maneja entre el $50 \mathrm{y}$ el $60 \%$ de las reservas totales. Ya actúa como subpotencia, adaptando el MERCOSUR a un juego multilateral, basado en coordinaciones estratégicas con Estados Unidos. Esta política deja poco espacio para la formación de un fondo financiero latinoamericano. ${ }^{7}$

El terremoto sufrido por el euro reforzaría, además, la aversión de los gobiernos brasileños a repetir, en la región, el papel jugado por Alemania en el Viejo Continente. Si la gran potencia germana quedó hundida en el atolladero de la Unidad Europea, Brasil tiene menos posibilidades de liderar una integración capitalista de Sudamérica.

\section{EL EXTRACTIVISMO EXPORTADOR Y SUS CONSECUENCIAS}

La gran dependencia regional del vaivén internacional de los precios de las materias primas acrecienta las críticas hacia el modelo exportador. Este esquema incentiva la multiplicación de emprendimientos exclusivamente destinados a comercializar productos básicos. Mientras crece la influencia del agro-negocio, las inversiones extranjeras consolidan la especialización petrominera. Todas las potencias buscan asegurarse el aprovisionamiento de insumos latinoamericanos, afianzando la inserción de la zona como granja o socavón de la economía mundial.

El término "extractivismo exportador" - que muchos analistas utilizan para describir este modelo-ofrece un acertado retrato del esquema actual. Destaca las nefastas consecuencias de la minera contaminante y la agricultura de exportación, en desmedro del abastecimiento interno. ${ }^{8}$ Este curso extractivo potencia la vulnerabilidad de América

\footnotetext{
${ }^{7}$ Berterretche (2011). Disponivel em: www.kaosenlared ${ }^{8}$ Esta la caracterización: "Articulación de movimientos
} sociales hacia el ALBA", 16-8-11, Buenos Aires. 
Latina sin generar necesariamente procesos de “reprimarización” o “desindustrialización”. Pero impone senderos frontalmente opuestos al desarrollo manufacturero que ha seguido el Sudeste Asiático. La atadura a las exportaciones básicas suscita, además, permanentes interrogantes sobre la continuidad del ciclo alcista de las materias primas, que comenzó en el 2003 y perdura hasta la actualidad.

Algunas explicaciones atribuyen esta valorización a los movimientos especulativos y a la falta de supervisión de los mercados agrícolas de futuro. La desregulación de esta plaza facilitó el ingreso de los bancos de inversión al negocio y la consiguiente presencia de un mortífero arsenal de derivados. El uso de instrumentos financieros en el sector aumentó de 500.000 millones (2000) a 13 billones de dólares (2008). ${ }^{9}$ Otras caracterizaciones destacan cómo el incremento del precio del petróleo potenció la expansión de los agro-combustibles y señalan que el 12\% de la producción mundial de maíz ya se destina a la fabricación de etanol. Una tercera explicación estima que la demanda china ha establecido un nuevo piso de cotizaciones para todas las materias primas. Esta diversidad de interpretaciones alude, en los hechos, a distintos procesos temporales. Mientras que las maniobras financieras determinan los incrementos coyunturales de precios, los agro-combustibles y las compras asiáticas inciden sobre el mediano y el largo plazo. también viejas controversias teóricas sobre el deterioro de los términos de intercambio y la influencia de las exportaciones primarias en el subdesarrollo latinoamericano. Pero cualquiera sean las respuestas a estos interrogantes, son evidentes los efectos sociales nocivos del extractivismo. Sólo el desarrollo manufacturero permitiría crear los puestos de trabajo necesarios para erradicar el atraso de la región. Este salto se encuentra impedido por la dominación que ejercen las empresas transnacionales de la economía latinoamericana.

Ese predominio determina incluso muchas posturas de política exterior. Cuándo Brasil y Ar-

${ }^{9}$ Munevar (2011) Disponível em: www.cadtm.org gentina rechazan el G 20 la regulación de los precios de los alimentos, siguen el mandato de las grandes compañías. La hambruna de los empobrecidos no es analizada con criterios de solidaridad, sino como una oportunidad de negocios. El extractivismo perpetúa el sometimiento del ciclo latinoamericano a la tiranía de la reproducción dependiente. Esta subordinación tiene mayor impacto actual en la esfera comercial o productiva, que en el área tradicional del endeudamiento. Pero la experiencia indica que la atadura a las exportaciones básicas termina recreando el agobio financiero.

\section{LA DESIGUALDAD Y LA EXPOLOTACIÓN: LOS SENTIDOS DEL DESEMPLEO}

Algunos economistas ponderan el rumbo actual destacando la caída de la desocupación que acompaña al crecimiento. Pero las cifras sólo indican reducidos cambios acordes al vaivén del ciclo. En la desaceleración del 2009, la tasa de desempleo llegó al 8,1\%, luego bajó al 7,3\% (2010), este año rondaría el 7\% y, si se confirman los augurios de freno, volvería a subir. Pero lo más relevante es la baja calidad de los nuevos empleos, reclutados en su gran mayoría en el sector informal. La precarización se mantiene como una norma, tanto de la recesión como de la prosperidad. Este deterioro complementa la degradación que imponen la disminución de las remesas, el éxodo rural y la marginalidad urbana. Millones de individuos están condenados a formas de supervivencia infra-humana, que logran visibilidad mediática sólo en los momentos de gran cataclismo (incendio de una cárcel superpoblada, alud en una favela, inundaciones en zonas desprotegidas).

La manifestación más dramática de este infierno en la región centroamericana es la expansión del narcotráfico. Esta actividad es un refugio de supervivencia para los campesinos endeudados y para los jóvenes desempleados incorporados a la delincuencia organizada. El macabro curso de la guerra emprendida por el gobierno de México ya cobró la vida de 50.000 personas. Con un estado de excepción permanente, se legaliza la brutalidad 
criminal que ejercitan las mafias y sus adversarios - cómplices del estado. ${ }^{10}$

La magnitud de las fortunas en juego es proporcional a la sangría de un negocio que manejan los clanes de la lumpen-burguesía. Este término se utilizó erróneamente en el pasado para retratar, en forma indiscriminada, a las clases dominantes latinoamericanas. Pero, en realidad, tipifica sólo a un sector muy específico, que ha transnacionalizado, diversificando y blanqueando las ganancias obtenidas en los circuitos paralelos de la acumulación. La burguesía lumpen está muy entrelazada con sus pares del sector formal, pero no integra el club estable de los grandes dominadores de la región.

Es sabido que el desgarramiento social padecido en América Latina recrea la pobreza y la desigualdad. Sin embargo, algunos analistas celebran la escasa reducción del nivel de inequidad registrado durante el reciente ciclo de crecimiento. Olvidan que América Latina continúa encabezando todos los récords internacionales de polarización social. La región incluye a cuatro de los países que lideran este vergonzoso indicador (Colombia, Bolivia, Honduras, Brasil). El coeficientes de Gini, que mide la desigualdad, ilustra un promedio zonal $(51,6)$ muy superior a media mundial $(39,5)$.

En este terreno, la principal novedad radica en la generalización de las políticas asistenciales, que tienden a atenuar los explosivos efectos de la fractura social. Todas las administraciones implementan estos planes como imperativos de gobernabilidad. El costo de estas acciones se asemeja en todos los países y es muy reducido en proporción al producto bruto.

En Argentina, rige la asignación universal (0,40\% del PIB), en Brasil, la Bolsa Familia (0,47\%), en México, el programa Oportunidades (0,51\%), en Bolivia, el Bono Juancito Pinto (0,33\%), en Venezuela, las Misiones (0,45\%), en Ecuador, el Bono de Desarrollo Humano (1.17\%), en Chile, el Plan Solidario (0,11\%), en Colombia, la Iniciativa Familias (0,39\%) y, en Perú, el Proyecto Juntos (0,14\%). ${ }^{11}$

\footnotetext{
${ }^{10}$ Petras (2010). Disponível em: www.ccun.org

${ }^{11}$ Gonçalves (2011). Disponível em: www.ie.ufrj.br
}

Este tipo de asistencia protege a los desamparados, pero no genera ninguna redistribución del ingreso. En la medida que coexiste con la precarización laboral, tiende más bien a convalidar la segmentación del mercado de trabajo. Esta fractura acentúa las viejas modalidades de superexplotación que caracterizan al capitalismo latinoamericano. Las empresas foráneas lucran en las maquilas con la baratura de la fuerza laboral, y los capitalistas locales exprimen a los asalariados, para compensar su escasa relevancia en el mercado global.

\section{LA ARGENTINA EN LA CRISIS: coyuntura y previsiones}

La desaceleración de la economía argentina es ya visible en muchos terrenos. La tasa del crecimiento sufre una abrupta caída y, en los próximos meses, se sabrá si el estancamiento desemboca en recesión. Hay un repliegue de la industria y de la construcción que acentúa la escasa creación de empleo de los últimos años y posibilita la destrucción de puesto de trabajo. Existen opiniones contrapuestas sobre la duración e intensidad del freno económico. Algunos analistas estiman que la paralización productiva será corta, si en el semestre en curso repunta el nivel de actividad del principal socio del país. Consideran que las medidas de estimulo fiscal adoptadas por el gobierno brasileño repercutirán positivamente sobre Argentina. También pronostican que el ciclo ascendente se reabrirá en el 2013, si se confirman las previsiones de cosecha récord con precios elevados. El aluvión de dólares resultante de esas ventas aliviaría las necesidades fiscales, en un ejercicio con menores vencimientos de la deuda pública.

Otros economistas describen un horizonte más sombrío, tanto por el agotamiento del ciclo precedente como por la ausencia de inversión privada. Pero nadie avizora la reaparición de una situación de colapso semejante al 2001-2002. Se debate el alcance que tendría una recesión, tomando la caída del 2009 como referencia comparativa. Resulta muy difícil explicar la coyuntura actual 
partiendo de un diagnóstico oficial, que retrata como "se nos cayó el mundo encima". En los hechos, ese impacto externo es limitado. Es cierto que el estancamiento de Brasil afecta seriamente a la exportación industrial. Pero la debacle europea tiene consecuencias reducidas, y el relativo aislamiento del sistema financiero local neutraliza los efectos del temblor bancario internacional.

Por otra parte, los precios por tonelada de la principal exportación argentina se ubican en un impensado récord de los 600 dólares por causas climáticas (sequía en Estados Unidos) y financieras (especulación con las materias primas). La duración de esa sorprendente apreciación es impredecible, pero contribuye a sostener la mejora del $24 \%$ que han registrado los términos de intercambio comercial desde el 2007. Los economistas del oficialismo relativizan estos datos y estiman que Argentina capea la tormenta global por su acertado manejo de las variables macro-económicas. Contrastan este comando con la desastrosa gestión que prevalece en la periferia europea. Comparan ambas situaciones y remarcan la capacidad que ha exhibido el país para enfrentar el mismo temporal, "sin recurrir al ajuste”. ${ }^{12}$ Esta caracterización no aclara por qué razón los gobiernos neoliberales de América Latina (Chile, Colombia, México, Perú) tampoco atraviesan por un período de ajuste. Afrontan una coyuntura parecida a la Argentina, aplicando estrategias económicas de apertura, privatización y flexibilidad laboral semejantes a sus pares europeos.

Es evidente que la crisis global tiene impactos distintos en cada región, en función del ciclo o la inserción financiero-comercial de cada país en la economía mundial. Por las mismas razones que la crisis capitalista incide en forma divergente en Estados Unidos y en China o en la India y Francia, la situación de América Latina difiere de Europa. Para comprender estecontraste, hay que evitar las analogías superficiales, que sólo buscan ponderar los méritos de una política económica en desmedro de otra. ${ }^{13}$

${ }^{12}$ Feletti (2012).

${ }^{13}$ Hemos explicado los impactos diferenciados de la crisis en dos textos recientes. Katz (2012b, 2012c).
El contrapunto entre Grecia o España con Argentina no es válido. Se equiparan economías que afrontan contextos objetivos muy disímiles. Lo pertinente sería contrastar la situación actual de esos países con nuestro colapso del 2001-2002. Sólo en ese momento Argentina soportaba un desmoronamiento equivalente y conviene recordar que, durante ese desplome, todos los oficialistas de turno (del PJ o la Alianza) eran ejecutores del ajuste. Sólo adoptaron la bandera del crecimiento cuando la crisis amainó. El uso de la tormenta financiera global como argumento político de ocasión induce a manipular las evaluaciones, en función de las conveniencias del momento. La misma coyuntura es utilizada para magnificar el torbellino (y justificar, por ejemplo, el adelantamiento de las elecciones), o para resaltar lo opuesto: la fortaleza de un modelo "blindado" frente a cualquier avatar internacional.

El análisis serio de lo que está ocurriendo exige, en cambio, constatar el efecto contradictorio de la crisis mundial sobre la economía argentina y las grietas internas del modelo actual. Este esquema ya dejó atrás el primer periodo de expansión sin obstáculos (2003-2008) y la segunda etapa de acotados desajustes (2009-2011).

\section{TRES FOCOS GENERADORES DE TENSIÓN EXPLOSIVA}

La inflación es el primer problema específico de la economía nacional. El absurdo encubrimiento de la carestía que realiza el INDEC impide transparentar la gravedad de este flagelo. Los índices provinciales ubican el ascenso de los precios en torno al $23 \%$ anual, y otras mediciones (encuestadoras privadas, índices barriales, cálculos del Congreso, consultoras oficialistas) estiman porcentajes semejantes.

La inflación está recreando un alarmante nivel de pobreza e indigencia y tiende a licuar la asignación universal. Podría, incluso, impactar sobre los salarios del sector formal, al des-actualizar los montos recientemente negociados en las 
convenciones colectivas. Lo que se acordó en las paritarias perderá vigencia si persiste la escalada de los precios. Este efecto puede ser muy significativo para la mitad de los asalariados en blanco que gana menos de 4000 pesos.

Muchos determinantes se conjugan para producir el resultado inflacionario, pero los precios principalmente aumentan para mantener la rentabilidad de las grandes empresas. Los grupos capitalistas concentrados aseguran sus beneficios con remarcaciones. Desde el 2008, la inflación ha reflejado fuertes restricciones de la oferta, que, a su vez, derivan del reducido nivel de inversión. Los precios han ascendido por una baja provisión de productos frente a una demanda recompuesta. Con la misma capacidad instalada ya no se pueden satisfacer mayores pedidos de compra. También la creciente emisión monetaria comienzaa emerger como un acelerador potencial de inflación. El ritmo de creación de dinero se ha multiplicado y la cantidad de pesos en circulación puede motorizar, como en el pasado, una inercia ascendente de los precios.

El segundo problema importante de la coyuntura es la continuada salida de capitales. Por pagos la deuda y remisiones de utilidades, el año pasado emigraron 13.500 millones de dólares, es decir el equivalente a todo el excedente comercial. Entre fines del 2007 y octubre 2011, el monto total de esos retiros alcanzó 80.000 millones de dólares. Esta sangría sólo quedó neutralizada por los 100.000 millones de dólares que generó la exportación. La magnitud de esa salida de capitales obedece a múltiples razones. Las filiales locales de las empresas extranjeras transfirieron enormes sumas de dinero a sus casas matrices, para compensar el deterioro imperante en las economías centrales. Además, muchas empresas locales continuaron diversificando inversiones en el exterior, mientras resguardan parte de su capital fuera del país.

La industria volvió a enfrentar, por otra parte, el típico cuello de botella externo que irrumpe al cabo de un ciclo de prosperidad. En esos períodos, se acentúa el déficit comercial de un sector que consume muchas divisas con la importación de componentes. Finalmente, la inédita avalancha de compras externas de combustible, que produjo la decreciente provisión interna de petróleo, determinó otro caudal de dólares perdidos. La continuada expectativa de devaluación que genera la brecha cambiaria acentúa la emigración de capitales. El denominado "retraso del dólar" obedece, en realidad, a un "adelanto de la inflación", que ha desarticulado la relación entre ambas variables. Desde el 2007, la cotización de la divisa se apreció un $43 \%$, frente a una escala de $189 \%$ de los precios internos.

El tercer problema severo del contexto actual es el desequilibrio fiscal. El superávit fiscal primario se ha esfumado, cualquiera sea la interpretación técnica del cómputo del desbalance (por el financiamiento que realizan el Banco Central y el ANSES). El excedente que rodeó al debut del modelo ha desaparecido, y el gobierno recurre a múltiples instrumentos para compensar esa pérdida. La ausencia de reformas impositivas progresivas es la principal causa del bache fiscal. Este cambio en la recaudación resulta indispensable para equilibrar, con nuevos ingresos, la significativa ampliación del gasto público. La perdurabilidad del viejo sistema regresivo ha dado lugar, en los últimos años, a un desfasaje insostenible, por la magnitud de los desembolsos oficiales en dos rubros muy deficitarios (energía y transporte).

El deterioro fiscal afecta duramente a las provincias, que incrementaron sustancialmente el empleo público (de 764.000 a 1,2 millones de empleados entre 2003 y 2012) y ahora no pueden financiar esa expansión. La plantilla salarial absorbe más de la mitad de esos presupuestos. El des-financiamiento provincial se acentuó, además, por la pérdida de los porcentuales recibidos en concepto de coparticipación federal. Este ingreso se redujo primero del 50,6\% del total (1993), al 34 $\%$ (2009) y últimamente al 32,7\% (2011). Frente al enorme rojo que afecta a las cuentas públicas de todo el interior, resulta poco creíble la explicación presidencial, que atribuye el desbalance a la ineficiencia de los gobernadores.

Esa interpretación omite que las mismas limitaciones fiscales golpean al gobierno nacional. 
Estas dificultades han determinado, por ejemplo, el retraso en la adaptación del mínimo no imponible al aumento de los salarios. Por esta razón, la incidencia del impuesto a las ganancias sobre los sueldos se ha transformado en un problema de envergadura. Más de 3 millones de trabajadores tributan un gravamen formalmente destinado a los beneficios empresarios. En muchos casos, ese pago absorbe un aguinaldo entero.

Las consecuencias de preservar un sistema tributario tan regresivo saltan a la vista. Las exenciones a la renta financiera y a las industrias promocionadas le restan anualmente al fisco 8900 millones de pesos. Esta suma supera con creces el costo fiscal de 3000 millones de pesos, que implicaría eliminar un gravamen a salarios tipificados como beneficios. Pero lo peor es la justificación oficialista de este impuesto como una penalidad a la "aristocracia obrera”. Afirman que este sector mejoró su nivel de ingresos y debe ampliar su contribución impositiva. Con ese criterio, se supone que la equidad avanzará con tributos a los trabajadores calificados y eximiciones a los financistas.

Hace algunos años, se utilizaba el mismo razonamiento para avalar el arancelamiento de las universidades estatales. Se afirmaba que la clase media debe pagar más que los pobres por el uso de un servicio público. De esta forma, se iguala para abajo y elude eliminar los privilegios impositivos que amparan a los grupos enriquecidos.

\section{EL TEATRO DE LAS POLÍTICAS DE AJUSTES}

La inflación, la salida de capitales y el déficit fiscal han complicado el escenario económico. El establishment presiona al gobierno para que implemente un fuerte atropello contra los trabajadores. Desde noviembre pasado, hacen valer esa exigencia en el mercado cambiario, a través de grandes compras de dólares. Los hombres de negocios plantean tres reclamos - corte de la emisión, devaluación y re-endeudamiento - a través de viejos voceros, que han vuelto a la pantalla (desde Broda hasta Cavallo). Despliegan sus recomendaciones apostando a la amnesia colectiva de lo ocurrido en los 90.

Los antiguos expertos de la Convertibilidad despotrican contra restricciones a las libertades económicas individuales, como si la economía capitalista funcionara sin estrictas regulaciones. Repiten la trillada comparación de la economía doméstica con su equivalente nacional, para recordar que "no se puede gastar más de lo que ingresa". Pero no sólo olvidan sus récords de endeudamiento. Omiten la diferencia cualitativa que separa a una familia - con recursos acotados - de un estado, con capacidad para incidir sobre el nivel general de actividad mediante políticas macro-económicas.

Los derechistas pronostican el "rodrigazo" y lo impulsan en la práctica. Buscan la auto-destrucción del gobierno actual, fantaseando con el retorno del neoliberalismo ortodoxo. Ante el desmoronamiento de las economías que elogiaban en la década pasada (como España o Irlanda), ahora convocan a imitar el modelo chileno, peruano o colombiano.

Pero lo más chocante es su despliegue de hipocresía. Los apologistas del libre-comercio cuestionan la “soja-dependencia” (Melconian, 2012). Los antiguos voceros de las AFJP alertan contra el “derroche del dinero de los jubilados". Los emporios periodísticos que lucraban con la privatización del sistema previsional titulan con las desgracias de la clase pasiva (Clarín). Los ex gerentes de bancos norteamericanos denuncian el aumento del endeudamiento público (Prat Gay). Algunos ajustadores reclaman directamente la devaluación (López Murhpy, 2012). Otros proponen lo mismo con fórmulas más elegantes. Hablan de “corrección cambiaria” (Frenkel), “ordenamiento de las variables desajustadas” (Lavagna, 2012) o eliminación del “cepo cambiario" (Llach, 2012) Todos ocultan que esa medida provocaría un deterioro inmediato de los ingresos populares. ${ }^{14}$ Ninguno propone reducir la inflación acotando la rentabilidad de los capitalistas. Recetan un enfriamiento de la economía que denominan "política antiinflacionaria eficaz” (Rapaport, 2012), o "sinceramiento de los precios" (Frigerio). Tampoco

${ }^{14}$ Melconian (2012); Lavagna (2012); Llach (2012); López Murphy (2012). 
se les ocurre corregir el déficit fiscal cortando las subvenciones a los grandes grupos. Sólo convocan a terminar con "la fiesta del gasto público" (Oppenheimer, 2012). Su verdadero objetivo es anular las mejoras sociales logradas en los últimos años. ${ }^{15}$

Los derechistas consideran pecaminoso reducir el desbalance de las cuentas públicos con algún impuesto a los acaudalados. Por esta razón, pusieron el grito en el cielo, ante el tibio revalúo rural realizado en la provincia de Buenos Aires, para actualizar valores de terrenos que tributaban siete veces menos que en 1984. Los economistas del establishment han hecho también un escándalo por el control de las importaciones (Sturzenegger), omitiendo que estas restricciones son la norma en sus ponderadas economías centrales. Algunos diarios (La Nación) llegan al extremo de advertir contra represalias norteamericanas o europeas, ignorando las barreras arancelarias que traban el ingreso de exportaciones argentinas a esos países. ${ }^{16}$

Para enmascarar el programa de ajuste, los medios de comunicación utilizan un concepto mágico: "recuperar la confianza". No aclaran que esa ansiada seguridad está exclusivamente dirigida a los grandes capitalistas. Su obsesión es "mejorar el clima de los negocios" con mayores protecciones a las ganancias. Los derechistas hacen campaña para reemplazar "la mala praxis" de la gestión actual por el manejo experimentado de los viejos gerentes del poder económico. Suponen que la satisfacción de los banqueros y de los industriales asegura el funcionamiento óptimo del sistema. Todavía no han percibido que la crisis global estalló con la aplicación de esas recomendaciones durante dos décadas de irrestricta práctica neoliberal.

\section{AMBIGUIDADES Y VACILACIONES DE LAS POLÍTICAS OFICIALES}

El gobierno ignora públicamente los problemas de la economía y difunde un imaginario escenario de prosperidad. Pero, en los hechos, toma

${ }^{15}$ Oppenheimer (2012). Rapaport (2012); Frigerio (2012).

${ }^{16}$ Sturzenegger (2012). en cuenta la agenda de los poderosos y ha oscilado entre el ajuste dosificado y acotado ("sintonía fina”) y el reciclaje de la reactivación con inflación. Vacila entre ambos rumbos y desenvuelve una administración a los tumbos, con gran dosis de improvisación. Hasta marzo pasado, impulsaba el torniquete mediante la fijación de estrictos techos a los aumentos salariales (18\%). Los discursos contra los sindicatos y las huelgas pavimentaban ese camino. Con ese propósito, se descalificó la lucha social y se multiplicaron las convocatorias a la pasividad de los trabajadores ("en Europa no bloquean el Palacio de la Moncloa”). Pero la suscripción de los convenios colectivos con aumentos superiores al 23\% debilitó esa estrategia. Los indicios de resistencia popular, en un contexto adverso a la confrontación con los asalariados, indujo al gobierno a cajonear su proyecto inicial. La conmoción creada por la tragedia de Once definió el viraje que debutó con la postergación del tarifazo al transporte.

La "sintonía fina" ha quedado reemplazada por un nuevo ensayo de reactivación basado en el consumo. La creciente gravitación del equipo de Kicilof confirma la preeminencia de esta opción. Apuestan a una desaceleración corta de la economía y a superar el bache actual con la misma política anti-cíclica que se aplicó en el 2009. Pero la viabilidad de esta repetición es dudosa. Hace tres años, existían amplios recursos fiscales y recién comenzaba la salida de capitales y la aceleración de la inflación. El colchón para adoptar medidas de gran impacto (como fue la asignación por hijo) se ha reducido, y las negociaciones con las empresas - para limitar los despidos a cambio de subsidiosserán complejas. Estas tratativas no han servido, además, para atenuar la remarcación de precios o remontar la caída de la inversión privada.

El gobierno intenta incentivar la demanda, regulando el ciclo y alentando la producción. Pero se han acumulado demasiados antecedentes de aplicación tardía y eficacia decreciente de esas medidas. No es lo mismo ensayar, en el 2012, lo que debía instrumentarse en el 2005 o el 2007. Este desfasaje se verifica en numerosos terrenos. 
El equipo gobernante ha decidido, en primer lugar, eludir la devaluación mediante una mayor pesificación de la economía. El objetivo declarado es canalizar los dólares circulantes hacia la actividad productiva y resguardar las divisas. Algunos economistas realzan, además, la necesidad patriótica de recuperar la primacía de la moneda nacional y convocan a ignorar los vaivenes del mercado paralelo. ${ }^{17}$ Pero la pesificación comienza cuando ya salieron gran parte de los dólares que debían custodiarse. Se toleró la fuga de capital, la remisión de utilidades y las erogaciones multimillonarias para adquirir combustible importado. Es indudable que el control de cambios es el punto de partida de una política de protección de la economía nacional frente a la inestabilidad global. Pero ese objetivo no se logra con acciones espasmódicas, arbitrarias y provisionales.

Un segundo ejemplo de reacción tardía es el anuncio de un plan de créditos para las viviendas, luego de años de aliento a construcciones de lujo que encarecieron la propiedad urbana, imposibilitando su acceso a los sectores populares. El nuevo programa no se financiará con impuestos a los capitalistas que se enriquecieron con la expansión inmobiliaria, sino con fondos del ANSES. Se argumenta que, volcando esa reserva a la construcción, habrá reanimación de la economía y mayor caudal de dinero para pagos futuros de las jubilaciones. Pero los mayores de edad necesitan mejoras inmediatas y no pueden esperar los frutos de esa prosperidad.

Si bien la cobertura total de la población se elevó significativamente (del 68\% en el 2005 al 91\% en el 2010), las jubilaciones promedio rondan el 40-50\% del sueldo medio. El 75\% cobra la mínima y muchos padecen la licuación de haberes sufrida entre el 2002 y el 2006. Existen, además, 266.000 juicios en espera de resolución y, cada año, se abona sólo un cuarto de las sentencias firmes. Es cierto que el dinero del ANSES debe ser invertido en actividades productivas internas, pero

${ }^{17}$ Rofman (2012) e Scaletta (2012) la prioridad es saldar las deudas pendientes con los mayores. Si continúa, además, la utilización de los recursos de la previsión social para los gastos corrientes del estado (asignación universal, programa conectar, déficit de provincias), el Fondo de Sustentabilidad corre un serio riesgo depreciación. El año pasado, aumentó 12,1\% frente a una inflación de $24 \%$. La decisión de obligar a los bancos a destinar un porcentaje de su cartera a los créditos de inversión, constituye un tercer ejemplo de medidas tardías e insuficientes. Durante años, el discurso industrialista no tuvo eco real en la actividad financiera. Los bancos ganaron fortunas con préstamos al consumo y operaciones de intermediación con títulos públicos. Algunos economistas señalan que las nuevas medidas de orientación crediticia son factibles recién ahora, que concluyó la reforma a la carta orgánica del Banco Central. Afirman que estos cambios amplían la posibilidad de utilizar las reservas en políticas anticíclicas. Sostienen que se puede, finalmente, adaptar la cantidad de dinero a las necesidades de la economía y no sólo a las metas de inflación. ${ }^{18}$

Cumplir con esos objetivos exigiría nítidas prioridades productivas para el uso de las reservas. Es cierto que se han eliminado los vestigios de convertibilidad y los ficticios criterios de independencia del BCRA. Pero se aceptan otros condicionamientos de gran envergadura, como son los pagos de la deuda externa con dólares atesorados. Se utiliza, además, una retórica engañosa para justificar esas erogaciones. La reciente la cancelación del BODEN 2012 constituye el ejemplo más reciente de esta actitud. La medida fue presentada como un acto patriótico ("sin deuda somos más libres"), que zanja una herencia ajena ("terminamos de pagar el corralito que nos dejaron otros"). Pero en los hechos se convalidó la socialización de pérdidas que ocasionó la devaluación con pesificación asimétrica del 2002. Esta compensación favoreció mucho más a los bancos que a los ahorristas, puesto que sólo el 23\% del segundo grupo pudo

\footnotetext{
${ }^{18}$ Heller, Carlos defiende el proyecto de reforma de la Carta Orgánica. Telam, 14 mar. 2012.
} 
retener los títulos. La mayoría debió liquidarlos a bajos precios. El pago de ese emblemático bono efectivamente aumentó la autonomía del gobierno para gestionar las finanzas públicas. Lo mismo ocurrió con la cancelación anticipada de la deuda al FMI. Pero lo importante es notar como ese margen de acción es utilizado para favorecer a los grupos capitalistas más concentrados.

El manejo de la actividad petrolera constituye un cuarto ejemplo de abordaje a destiempo de los problemas, achacando la culpa a otros. Durante ocho años, el gobierno desoyó las incontables denuncias del saqueo perpetrado por REPSOL. Se elogiaba a la empresa, convalidando un vaciamiento que sólo en la Cuenca Neuquina dejó una deuda ambiental 5000 millones de dólares. La estatización sobrevino cuando la pérdida del auto-abastecimiento, la caída de las reservas y los gastos de importaciones crearon una situación insostenible. La estrategia petrolera actual constituye una gran incógnita. Por un lado, se designó al frente de YPF a un gerente de las petroleras privadas (Gallucio), que aspira a concertar contratos privilegiados con esas compañías, aumentando los precios en boca de pozo. Por otra parte, se ha extendido el control estatal sobre todas las inversiones y ganancias del sector, revirtiendo la libre-disponibilidad del crudo, mientras se suscriben interesantes convenios de asociación con PDVSA. Estos vaivenes en el manejo de los hidrocarburos siguen la misma pauta ambivalente que impera en el ámbito de la moneda, la producción o las finanzas.

\section{CONFLUENCIAS ENTRE PARADIGMAS DISTINTOS}

La política económica del kirchnerismo oscila junto a los grandes desequilibrios que afectan a la economía argentina. El oficialismo intenta gestionar estas tensiones sin revertir sus causas. No modifica la fragilidad de la estructura productiva nacional y, en varios terrenos, acentúa esa vulnerabilidad. El modelo avala la creciente dependencia de un mono-cultivo que expande su preeminencia. La soja se extiende con deforestación y agro-tóxicos hacia toda la superficie agrícola, generando desalojo de campesinos, concentración de tierra y reducción del número de explotaciones. El mismo impacto produce la ampliación de la mega-minería a cielo abierto, que amenaza la provisión del agua proveniente de los glaciares. Esta actividad destruye cultivos tradicionales y afianza "economías de enclave" manejadas por compañías transnacionales, que no generan empleo, ni pagan impuestos acordes a su actividad. Este perfil extractivo ha quedado agravado por la escasez de combustible, que sucedió a la pérdida del auto-abastecimiento. La falta de petróleo y gas obstruye el desenvolvimiento de la economía.

$\mathrm{Al}$ cabo de ocho años de alto crecimiento, tampoco se observa un efectivo repunte de la industria. El sector manufacturero se ha expandido bajo el impulso de los vaivenes cíclicos, sin corregir su escasa diversificación, elevada concentración, continuada extranjerización y sistemática transferencia de utilidades al exterior. Por estas razones reaparecieron las viejas restricciones que afectan a un sector altamente dependiente, sectorialmente fracturado y comercialmente deficitario. Las importaciones aumentan a un ritmo superior a las ventas externas y perdura la decreciente integración de componentes nacionales. El modelo funciona convalidando una lógica capitalista de alta rentabilidad, que promueve la fabricación de autos en lugar de trenes y la construcción de torres residenciales en desmedro de complejos habitaciones populares. Se ha privilegiado el consumo de altos ingreso y no el desarrollo productivo.

Es cierto que, en este marco, se consumó la recuperación de importantes conquistas populares. La política oficial convalidó, en este terreno, la vigencia de relaciones sociales de fuerza más favorables a los asalariados. Por esta razón, los sueldos del sector formal aumentaron al compás de la inflación. Pero esos logros de los trabajadores registrados no se han extendido al resto de los asalariados. Al contrario, se afianza la fractura en- 
tre empleados inscriptos con protección social y precarizados carentes de cualquier cobertura. La masa de informales continúa padeciendo terribles condiciones de explotación laboral y paupérrimos ingresos. La existencia de un gasto social mayúsculo confirma la gravitación del asistencialismo y la escasa inclusión de los desamparados. La desigualdad se mantiene en niveles semejantes a la mitad de los 90, y sería ingenuo suponer que el modelo es ajeno estos resultados.

Algunos partidarios del oficialismo ignoran estos problemas, otros repiten el latiguillo de la "herencia recibida", y ciertos analistas estiman que las dificultades son mucho menores que los logros alcanzados. Sustentan esta opinión en el fuerte rechazo que suscita el modelo entre los críticos derechistas y el significativo elogio que despierta entre los economistas progresistas del exterior. Estiman que ambas reacciones corroboran el tránsito por el buen sendero. ${ }^{19}$ Pero este contrapunto sólo ilustra cómo se han polarizado las opiniones entre el esquema neo-desarrollista vigente y los planteos de la ortodoxia neoliberal. Estas dos opciones son vistas como los únicos cursos factibles y, por eso, se debate exclusivamente las diferencias entre ambos modelos. Las distinciones más resaltadas son la política económica (tracción de la economía por la demanda o la inversión), la gestión del estado (regulación o privatización) y los intereses dominantes en disputa (grupos agro-industriales versus financistas).$^{20}$ Pero, al enfatizar sólo esas divergencias, se pierde de vista los múltiples vasos comunicantes que enlazan a los dos proyectos. Este parentesco obedece, en gran medida, a la impronta conservadora que presenta el neo-desarrollismo contemporáneo. Esta corriente es reacia a cualquier redistribución real de los ingresos que mejore el nivel de vida popular a costa de los beneficios empresarios. Por esta razón, no reduce la desigualdad con medidas de progresividad impositiva.

La brecha social no podrá achicarse sin afectar las ganancias que el modelo actual promueve, como un motor del desarrollo económico. Los teóricos

${ }^{19}$ Aronskind (2012),

${ }^{20}$ Katz (2010). neo-desarrollistas desconocen este hecho porque mantienen una mirada idílica del capitalismo y suponen que el aliento del lucro es plenamente compatible con mejoras significativas y sustentables de las mayorías populares. Pregonan el avance hacia el bienestar de todos los ciudadanos mediante el perfeccionamiento de las instituciones políticas vigentes, como si los conflictos sociales y los antagonismos de clases fueran anécdotas del pasado.

El neo-desarrollismo argentino constituye

la avanzada regional de una concepción que está ganando terreno en varios países latinoamericanos, ante el creciente desprestigio del neoliberalismo. Comienza, incluso, a prosperar en Brasil, a través de una modalidad hibrida que despuntó en el segundo mandato de Lula. ${ }^{21} \mathrm{~A}$ diferencia del viejo desarrollismo, sus promotores actuales subordinan la industrialización a la exportación de bienes primarios y no canalizan la renta captada por el estado hacia el desarrollo de empresas públicas. Tampoco jerarquizan el mercado interno y aceptan la reinserción pasiva de América Latina como proveedor internacional de minerales, alimentos o combustible. El neo-desarrollismo sintoniza con los sectores de las clases dominantes que han internacionalizado sus fuentes de lucro. Promueve los negocios de estos grupos mediante intervenciones más activas del estado, mayor coordinación regional y creciente autonomía financiera. Inscribe todos sus proyectos en la nueva etapa de mundialización capitalista y abandonó las veleidades antiimperialistas del pasado.

\section{¿REENCONTRARÁ FUERZAS PARA RESURGIR LA BURGUESIA NACIONAL?}

Los defensores del modelo ponderan la recuperación de un manejo soberano de la economía, pero nunca aclaran quiénes son los principales beneficiarios de esa gestión. En lugar de especificar estos sujetos, responden con generalidades (toda la sociedad), con reminiscencias nacionalistas (el país, la patria), o con alusiones

${ }^{21}$ Boito (2012) Disponível em: www.brasildefato.com.br. Saad Filho; Morais (2011) 
tangenciales a las mayorías (el pueblo). Sólo algunos economistas reconocen que el principal objetivo social del esquema en curso es recrear la burguesía nacional, que tantas veces ponderó Kirchner. Pero este propósito choca con la inexistencia de grupos capitalistas de envergadura exclusivamente centrados en la acumulación local y el mercado interno. Los distintos segmentos de ese empresariado ya no ocupan lugares preeminentes en la cúspide del poder económico. El establishment ha quedado muy configurado por grupos exportadores y firmas diversificadas, con grandes capitales e intereses en el exterior.

En los últimos ocho años, se utilizaron cuantiosos recursos del estado para alentar el resurgimiento de la burguesía nacional, esperando que apuntale el desenvolvimiento del modelo. Esas subvenciones fueron íntegramente costeadas por los sectores populares, y el resultado ha sido decepcionante. Nuevamente se repitióla infructuosa experiencia de un "capitalismo de amigos", que dilapida recursos y obstruye la industrialización. Analistas muy afines al esquema actual reconocen este fallido resultado. ${ }^{22}$ La sucesión de escándalos de corrupción constituye una expresión de este fracaso. Las coimas son un condimento insoslayable de cualquier estrategia de forjar una clase de capitalistas con prebendas del sector público. Pero el montaje de negocios paralelos a la regulación estatal ha florecido sin ninguna contrapartida de inversión privada o expansión productiva.

El caso Ciccione representa el más reciente de estos negociados. Como involucra al vicepresidente - en un tema tan sensible como es la impresión de moneda -, alcanzó gran resonancia. El choque entre el grupo apadrinado por Boudou y el sector competidor de Boldt (protegidos por varios gobernadores) ha sido acompañado por la secuencia habitual de enriquecimiento de altos funcionarios. El ruido que han hecho los medios de comunicación enemistados con el gobierno (como Clarín) es proporcional al silencio que mantienen cuando los negociados afectan sus

${ }^{22}$ Zaiat (2012, p.1-4). propios intereses (fondos de pensión, agroindustria, papel prensa).

En cualquier caso, lo importante es notar la existencia de un gran entramado de grupos capitalistas, que lucran con el modelo neo-desarrollista sin recrear la esperada burguesía nacional. Esos sectores son agraciados con subvenciones oficiales que atesoran, despilfarran o fugan, sin consumar las inversiones que prometen. Frente a estos desengaños, la reacción oficial ha sido el reemplazo de un incumplidor por otro sustituto de la misma especie. Últimamente, habrían quedado desplazados Britos, Eurnekian y Mindil, mientras Cristóbal López sigue en carrera y se buscan nuevos aliados para los baches dejados en varias actividades (petróleo, electricidad, carreteras) ${ }^{23} \mathrm{Lo}$ ocurrido con el ferrocarril es particularmente ilustrativo de esta tendencia oficial a sustituir un socio en desgracia por algún reemplazante de la misma plantilla. Luego de la tragedia de Once le quitaron la concesión a Cirigliano para transferírsela a Roggio-Romero. Este enroque preserva la misma estructura vigente desde hace décadas, con el auspicio mafioso de los mismos funcionarios y burócratas sindicales integrados a la UGOFE. Se demostró que un "estado presente" puede resultar tan pernicioso como su contraparte "ausente", si contribuye a organizar negociados (Jaime) y a convalidar complicidades (Schiavi).

Los economistas K continúan debatiendo por qué razón está bloqueada la reaparición de los empresariados virtuosos que observan en otras latitudes. Algunos consideran que existe un determinante histórico difícil de remover, en un país conformado en torno a la renta agraria. Otros estiman que, perfeccionando los sistemas de control estatal, se logrará modificar el patrón de capitalistas argentinos reacios a la inversión o al riesgo y acostumbrados al lucro de corto plazo.

Nadie sabe sialguna vez reaparecerála esperada burguesía nacional. Pero desojar la margarita tiene su costo, ya que el gobierno destina monumentales subvenciones a ese proyecto. Si transparentaran

23 "La rueda de la fortuna de los empresarios K", La Nación, 17 ju. 2012. 
esas cifras, resultaría muy difícil defender públicamente semejante dispendio. En última instancia, el problema económico y social de Argentina no radica en la modalidad de capitalismo predominante, sino en la continuidad de un sistema que genera explotación, sufrimientos e injusticias. Los males del capitalismo no se corrigen buscando otro capitalismo.

\section{¿UNA ALTERNATIVA POPULAR ES POSIBLE? CONFUSIONES Y POSIBILIDADES}

La prioridad que asigna el neo-desarrollismo al fortalecimiento de los grupos empresarios locales obliga a postergar la satisfacción de muchas demandas sociales. Los fondos públicos derivados a la actividad privada son retraídos de su utilización popular. Afortunadamente, los trabajadores y los movimientos sociales continúan con sus peticiones, sin quedar paralizados por las metas burguesas que auspicia el oficialismo. Esta intensa práctica de movilizaciones, piquetes y huelgas continúa junto al importante nivel de combatividad que caracteriza a los trabajadores argentinos. Pero esta acción no se traduce en proyectos propios, contrapuestos a las distintas vertientes políticas que propician estrategias neoliberales o neodesarrollistas. La gestación de un tercer polo - que rompa el aprisionamiento a esas dos opciones de las clases dominantes - es una asignatura pendiente de la izquierda y del progresismo genuino.

Para avanzar en esa construcción, resulta indispensable evitar que las críticas al gobierno se confundan con los cuestionamientos que propaga la reacción neoliberal. Es vital explicitar esa diferenciación, en el actual contexto de bombardeo mediático derechista. El establishment busca difundir la imagen de objeciones uniformes, complementarias y compatibles de todos los opositores, contra un enemigo gubernamental común. Esta estrategia de confusión privilegia especialmente la temática económica. Durante los últimos años, muchos críticos centroizquierdistas del kirchnerismo coquetearon, adrede o en forma involuntaria, con ese operativo. Últimamente, esta actitud se ha modificado, pero no ha desaparecido. Algunos todavía resisten al registro de las diferencias que separan al gobierno de los neoliberales. Ese desconocimiento es fatal y conduce al desconcierto, cada vez que el oficialismo adopta alguna medida limitadamente progresiva (como la reciente expropiación de YPF). La desubicación es aún mayor entre quiénes repiten el libreto de los medios contra el "autoritarismo", la "caja” o el "populismo" presidencial. En la izquierda, se observan casos más extremos de esta ceguera. Ciertos críticos han invertido por completo la interpretación de los sucesos económicos y caracterizan a la pesificación como el debut de un "rodrigazo" y a la nacionalización de YPF como un anticipo de la reprivatización de esa compañía. Emiten, además, pronósticos de estallidos financiero o cambiario en estricta sintonía con el guión del establishment. ${ }^{24}$

Esta confusión proviene de presentar los conflictos que involucran intereses nacionales o populares como simples disputas inter-capitalistas. También deriva de la incapacidad para percibir las conquistas sociales o democráticas que se han obtenido en los últimos años. Con esa postura, no se pueden tender puentes hacia las mayorías populares, que observan con simpatía al gobierno actual. A pesar de la polarización que se ha creado entre el universo $\mathrm{K}$ y anti-K, los sectores politizados de la población escuchan con atención los mensajes de la izquierda y del progresismo. Pero la recepción efectiva de estos planteos depende de la calidad y la formulación que tienen esos mensajes. ${ }^{25}$

Hay buenas condiciones para avanzar hacia la construcción de una tercera alternativa genuinamente popular. Pero hay que afinar la puntería, mejorar las propuestas alternativas y profundizar la elaboración colectiva.

Recebido para publicação em 05 de janeiro de 2013 Aceito em 30 de março de 2013

\footnotetext{
${ }^{24}$ Altamira (2012, p.5-7).

${ }^{25}$ El reciente documento de los Economistas de Izquierda (EDI) se ubica en esta perspectiva. "Afloran floran los límites
} del modelo". www.rebelion.org/mostrar., 04 abr. 2012. 


\section{REFERÊNCIAS}

ALtAmiRA, Jorge. El arte de pensar en pesos. Prensa Obrera, Buenos Aires, 1224, 31 mayo 2012.

ARONSKIND, Ricardo. El rechazo de la derecha empresaria, Página12, Buenos Aires, 25 mar. 2012.

BERTERRETCHE, Juan, ¿Acuerdo económico defensivo? 19 ago. 2011. Disponível em: www.kaosenlared.

BOITO, Armando. A economia capitalista está em crise e as contradições tendem a se aguçar. Jornal Brasil de Fato, São Paulo, 09 abr. 2012. Disponível em: www.brasildefato.com.br

CEPAL/OIT. Coyuntura laboral en América Latina y el Caribe, n.5, jun. 2011. Disponível em: www.oit.org.pe

FELETTI, Roberto. Argentina redobla la apuesta. Página12, Buenos Aires, 23 jul. 2012.

FRIGERIO, Rogelio. Comparar a veces es engañoso, Clarín, Buenos Aires, 11 mayo, 2012

GONÇAVES, Reinaldo. Redução da desigualdade da renda no governo Lula. Analisis Comparativo, Rio de Janeiro, 20 jun. 2011. Disponível em: www.ie.ufrj.br

LAVAGNA, Roberto. Estamos frente a una economía en falsa escuadra. Clarín, Buenos Aires, 06 jun. 2012.

LÓPEZ, Murphy Ricardo. Qué esconde la reforma al Banco Central. Clarín, Buenos Aires, 19 mar. 2012.

KATZ, Claudio. The singularities of Latin America. The crisis and the left. Socialist Register, Toronto, v.48, 2012a,.

. El ajedrez global de la crisis. Batalla de Ideas, Buenos Aires, v.3, n.3, 2012b.

. Los atolladeros de la economía latinoamericana In: . El neoliberalismo y su crisis. Causas, escenarios y posibles desenvolvimientos. Santiago de Chile, ARCIS/ REDEM, 2012c

. Los nuevos desequilibrios de la economía argentina, Anuario EDI, Buenos Aires, n.5, sep. 2010.

KULFAS, Matías. Que integración regional conviene. Página12, Buenos Aires, 20 jun. 2011
LLACH, Juan José. Para no tentar a una nueva crisis. La Nación, Buenos Aires, 24 mayo 2012.

MELCONIAN, Carlos. Otra vez la revolución conservadora. La Nación, Buenos Aires, 29 jul. 2012.

MONIZ BANDEIRA, Luiz Alberto. A crise afeta a todos os países inclusive Brasil, ALAI, Brasília, 29 ago. 2011.

MUNEVAR, Daniel. Alzas en los precios de alimentos. Una mirada desde América Latina, CADTM AYANA, jun. 2011. Disponível em: www.cadtm.org

OPPENHEIMER, Andrés. Argentina economic fiesta is over, Miami Herald, 18 jun. 2012.

PÁEZ, Pedro. Detrás del desorden económico mundial, Página12, Buenos Aires, 03 out. 2011.

PETRAS, James. Latin America: Road to 21 st century capitalist development, oct. 25, 2010. Disponível em www.ccun.org

RAMAL, Marcelo. La izquierda independiente saluda la nueva YPF. Prensa Obrera, Buenos Aires, 1219, 05 jul. 2012 .

RAPAPORT, Luis. Cristina: con quién pesificará sus dólares. Clarín, Buenos Aires, 08 jun. 2012.

ROBBA, Alejandro. El desafío de la integración financiera regional, Página12, Buenos Aires, 07 ago. 2011.

ROFFMAN, Alejandro. Una mirada distinta, Página12, Buenos Aires, 22 jul. 2012.

SAAD FILHO, Alfredo; MORAIS, Lecio. Da economia política a política econômica: o novo-desenvolvimentismo e o governo Lula. Revista de Economia Política, São Paulo, v.31, n.4, out./dez. 2011

SCALETTA, Claudio. Desdolarización y tendencia, Página12, Buenos Aires, 15 jul. 2012.

STURZENEGGER, Federico. Los seis errores de la economía K, La Nación, Buenos Aires, 10 jun. 2012.

TOVAR, Eudomar. Consejo Monetario del ALBA. No podemos evitar el impacto, Página12, Buenos Aires, 03 oct. 2011.

ZAIAT, Alfredo. Burguesía fallida, Página12, Buenos Aires, 01 abr. 2012. 


\section{MANIFESTATIONS OF THE CRISIS IN LATIN AMERICA AND THE PARADOXES OF ARGENTINE NEO-DEVELOPMENT}

\author{
Claudio Katz
}

The worsening global crisis has made it clear that the Latin American economy's power to contain turbulence is limited. UNASUL's central role has increased, but the stabilization fund has not been able to prevent the foreign influence on the finances and stagnation of the Banco do Sul. Its enormous currency reserves will end up bailing out European banks if their common currency's luck does not improve. The practice of extracting natural resources for export keeps the economy from following the Asian countries' example of developing manufacturing and also reinforces the predominance of transnational companies. Social welfare programs do not reduce inequality, nor do they change super-exploitation, while the narcotraffic lumpen proletariat increases the potential for social marginalization. Neo-liberal prestige has revived neo-developmentalist focuses, but the substitution of the old Argentine bourgeoisie by export groups has hindered projects for re-industrialization. Within this context, a third alternative truly representative of the people is being delineated.

\section{MANIFESTATIONS DE LA CRISE EN AMÉRIQUE LATINE ET LES PARADOXES DU NEODÉVELOPPEMENT ARGENTIN}

\author{
Claudio Katz
}

L'aggravation de la crise mondiale accentue les limitations de l'économie latino-américaine pour en modérer la turbulence. La centralité de l'UNASUL augmente, mais le fond de stabilisation ne diminue pas l'étrangéisation des finances et la stagnation de la Banque du Sud. Les réserves, énormes, finiront par porter secours aux banquiers européens si les chances d'une monnaie unique n'aboutissent pas. L'extractivisme exportateur empêche de reproduire le développement des manufactures asiatiques et renforce la prédominance de sociétés transnationales. Les plans d'assistanat ne réduisent pas les inégalités ni ne modèrent la super-exploitation alors que la lumpen-bourgeoisie du narcotrafic potentialise la marginalité sociale. Le manque de prestige néolibéral a ressuscité les propositions basées sur le néo-développement, mais le remplacement des vieilles bourgeoisies nationales par des groupes exportateurs rendent difficiles les projets de réindustrialisation. Dans ce contexte, une nouvelle trajectoire se dessine, celle d'une troisième voie réellement populaire.

KEY WORDS: Crisis. Transnational neoliberalism. Mots-CLÉs: Crise. Néolibéralisme transnational. Neodevelopmentalism. Latin America. Argentina. Néo-développement. Amérique Latine, Argentine.

Claudio Katz - Economista. Doutor pela UBA. Professor do Departamento de Historia Universidade de Buenos Aires (UBA). Membro da Carrera de Investigador Científico y Tecnológico (CONICET), como Investigador Independente. Coordenador do Programa Universidade UBA. Integra o Núcleo de Pesquisa, desenvolvendo pesquisas na área de Economia Política Suas mais recentes publicações, são: Interpretaciones de la crisis, la crisis capitalista mundial y América Latina. CLACSO- Colección Grupos de Trabajo, pag 1936. Buenos Aires, 2012; Licoes da Argentina para Grécia, Quem Paga o Estado Social em Portugal. Lisboa: Bertrand Editora, 2012, pag 357-374; Bajo el imperio del capital. Edición argentina, Luxemburg, diciembre de 2011; La economía marxista, hoy. Seis debates teóricos. Madrid: Maia Ediciones. 2009, pags 213. 